\title{
IN SITU SYNTHESES AND CHARACTERIZATION OF TWO PHASES OF A COPPER COMPLEX: STRUCTURAL DIFFERENCE LEADING TO DIFFERENT PROPERTIES
}

\author{
Xiu-Guang YI, ${ }^{\mathrm{a}, \mathrm{b}^{*}}$ Xiao-Niu FANG, ${ }^{\mathrm{a}}$ Xiao-Ying ZHOU, ${ }^{\mathrm{c}}$ Yong-Xiu $\mathrm{LI}^{\mathrm{b}}$ and Yan-Zhu LIU ${ }^{\mathrm{b}, *}$ \\ anstitute of Applied Chemistry, Jiangxi Province Key Laboratory of Coordination Chemistry, School of Chemistry and Chemical \\ Engineering, Jinggangshan University, Ji'an, Jiangxi 343009, China \\ ${ }^{\mathrm{b}}$ School of Materials Science and Engineering \& School of Chemistry, Nanchang University, Nanchang, Jiangxi 330000, China \\ ${ }^{\mathrm{c}}$ School of New Energy Science and Engineering, Xinyu University, Xinyu, Jiangxi 338004, China
}

A copper complex possessing two phases, i.e. $\alpha$ phase 2,2'-dimethyl-2,2'bipyridinium tetrachloro-copper(ii) $\alpha-\mathrm{CuCl}_{4}\left(\mathrm{~N}, \mathrm{~N}^{\prime}\right.$-dimethyl-2,2'- $\mathrm{H}_{2}$ bipy) (1) and $\beta$ phase 2,2'-dimethyl-2,2'-bipyridinium tetrachloro-copper(ii) $\beta$ $\mathrm{CuCl}_{4}\left(\mathrm{~N}, \mathrm{~N}^{\prime}\right.$-dimethyl-2,2'-H $\mathrm{H}_{2}$ bipy) (2) has been synthesized via solvothermal reactions and structurally characterized by single-crystal X-ray diffraction. Complex 1 crystallizes in the space group $C 2 / c$ of the monoclinic system with four formula units in a cell: $a=16.4981(12), b=7.9064(4), c=13.2230(7) \AA$, $\beta=116.967(6)^{\circ}, V=1537.27(16) \AA^{3}, D_{c}=1.701 \mathrm{~g} / \mathrm{cm}^{3}, S=1.062, R=0.0264$ and $w R=0.0659$. Complex 2 crystallizes in the space group $F d d 2$ of the orthorhombic system with sixteen formula units in a cell: $[a=25.625(2)], b=$ 31.7054(15), $c=7.7164(4) \AA, V=6269.1(7) \AA^{3}, D_{c}=1.668 \mathrm{~g} / \mathrm{cm}^{3}, S=1.030$, $R=0.0305$ and $w R=0.0695$. Complex 1 is characteristic of an isolated structure and a two-dimensional (2-D) supramolecular layer, while complex 2 features an isolated structure and a three-dimensional (3-D) supramolecular

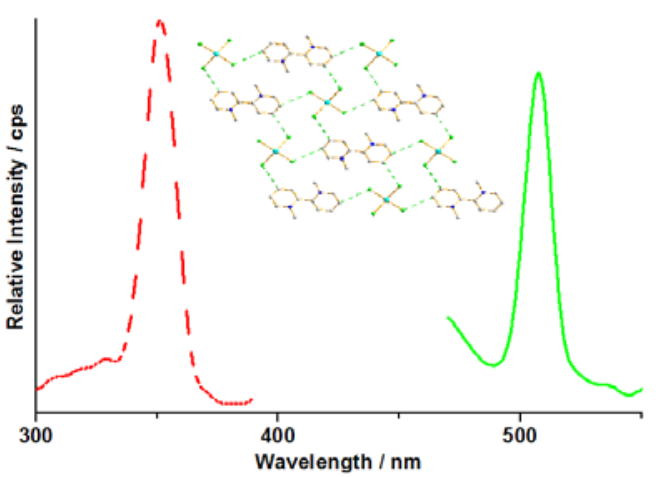
framework. Photoluminescent investigation reveals that they display emissions in the green (1) and red (2) regions. Optical absorption spectra reveal the presence of an energy band gap of $1.53 \mathrm{eV}$ and $2.23 \mathrm{eV}$ for $\mathbf{1}$ and 2, respectively.

\section{INTRODUCTION}

In recent years, supramolecular chemistry has gained more and more attention to synthesize new complexes, because it can take advantage of selfassembly to prepare complexes by virtue of weak inter/intramolecular interactions, for example, hydrogen bondings, $\pi$ - $\pi$ stacking and dipole-dipole interactions to connect building blocks together and a great numbers of supramolecular complexes have thus far been reported. ${ }^{1-6}$ To our knowledge, metal bipyridine complexes have attracted increasing attention, due to both their intrinsic aesthetic aspect and their wide applications. ${ }^{7-11}$ Because the pyridyl rings of the bipyridine possess a delocalized $\pi$-electron system, bipyridine is a good ligand for designing and preparing light emitting complexes that can be applied in various fields such as organic light emitting diodes, chemical sensors, as well as solar energy conversion. Furthermore, as a bifunctional ligand, bipyridine can act as a bidentate ligand to link several metal centers and a useful moiety for building supramolecular complexes. Our recent efforts in investigating metal bipyridine complexes are mainly aimed at the complexes that have

\footnotetext{
*Corresponding author: jayxgggchem@163.com
} 
potentially semiconductive and photoluminescent properties. In this paper, we report the syntheses, crystal structures, and semiconductive and photoluminescent properties of a copper complex with two phases, i.e. $\alpha$ phase 2,2'-dimethyl-2,2'bipyridinium tetrachloro-copper(ii) $\alpha-\mathrm{CuCl}_{4}\left(\mathrm{~N}, \mathrm{~N}^{\prime}-\right.$ dimethyl-2,2'- $\mathrm{H}_{2}$ bipy) (1) and $\beta$ phase 2,2'dimethyl-2,2'-bipyridinium tetrachloro-copper(ii) $\beta$ - $\mathrm{CuCl}_{4}\left(\mathrm{~N}, \mathrm{~N}^{\prime}\right.$-dimethyl-2,2'- $\mathrm{H}_{2}$ bipy) (2). It should be pointed out that they have different structural geometries which lead to different properties.

\section{EXPERIMENTAL}

All reactants of A.R. grade were commercially obtained and used without further purification. Elemental analysis of carbon, hydrogen and nitrogen was performed on an Elementar Vario EL elemental analyzer. The infrared spectrum was measured on a PE Spectrum-One FT-IR spectrophotometer over the frequency range $4000 \sim 400 \mathrm{~cm}^{-1}$ by using the $\mathrm{KBr}$ pellet technique. Photoluminescence experiments are carried out using the solid state powder at room temperature on a F97XP spectrometer. The UV-vis spectra were recorded at room temperature on a computercontrolled TU1901 UV-vis spectrometer equipped with an integrating sphere. $\mathrm{BaSO}_{4}$ plate was used as a reference $(100 \%$ reflectance), on which the finely ground powder of the samples were coated. The absorption spectra were calculated from reflection spectra by the Kubelka-Munk function: ${ }^{12,13}$ $\alpha / S=(1-R)^{2} / 2 R, \alpha$ is the absorption coefficient, $S$ is the scattering coefficient which is practically wavelength independent when the particle size is larger than $5 \mu \mathrm{m}$, and $R$ is the reflectance.

Synthesis of (1): This complex was prepared by mixing $\mathrm{CuCl}(2 \mathrm{mmol}, 0.198 \mathrm{~g}), 2,2$-bipy (1 mmol, $0.156 \mathrm{~g}), 2 \mathrm{~mL}$ methanol, $0.5 \mathrm{~mL}$ concentrated hydrochloric acid and $10 \mathrm{~mL}$ distilled water in a $25 \mathrm{~mL}$ Teflon-lined stainless steel autoclave and heated at $200{ }^{\circ} \mathrm{C}$ for ten days. After being slowly cooled to room temperature, yellow prismatic crystals suitable for X-ray analysis were obtained. $\mathrm{C}_{12} \mathrm{H}_{16} \mathrm{Cl}_{4} \mathrm{CuN}_{2}$ : calc. C, 36.62; H, 4.10; N, 7.12; Found C, 36.71; H, 4.06; N, 7.20. The yield was $30 \%$ (based on copper). IR peaks $\left(\mathrm{cm}^{-1}\right)$ : 3439(vs), 3154(w), 3098(w), 3076(m), 1878(w), 1624(vs), $1580(\mathrm{~m}), 1503(\mathrm{~s}), 1455(\mathrm{~s}), 1400(\mathrm{w}), 1321(\mathrm{w}), 1282(\mathrm{~m})$, 1178(s), 1148(w), 1114(w), 1014(w), 906(w), 772(vs), 647(w), 534(w), 505(w) and 434(w).

Synthesis of (2): This complex was prepared by mixing $\mathrm{CuCl}(2 \mathrm{mmol}, 0.198 \mathrm{~g}), 2,2$ '-bipy ( $2 \mathrm{mmol}, 0.312 \mathrm{~g}), 2 \mathrm{~mL}$ methanol, $0.5 \mathrm{~mL}$ concentrated hydrochloric acid and $10 \mathrm{~mL}$ distilled water in a $25 \mathrm{~mL}$ Teflon-lined stainless steel autoclave and heated at $180{ }^{\circ} \mathrm{C}$ for one week. After being slowly cooled to room temperature, yellow block-like crystals suitable for X-ray analysis were obtained. $\mathrm{C}_{12} \mathrm{H}_{16} \mathrm{Cl}_{4} \mathrm{CuN}_{2}$ : calc. C, 36.62; H, 4.10; N, 7.12; Found C, 36.74; H, 4.07; N, 7.19. The yield was $27 \%$ (based on copper). IR peaks $\left(\mathrm{cm}^{-1}\right)$ : 3439(vs), 3149(w), 3095(m), 3011(m), 1867(w), 1628(vs), 1598(s), 1520(s), 1472(vs), 1455(s), 1399(m), 1290(m), 1238(w), 1178(s), 1139(w), 1110(w), 1074(w), 1040(w), 1018(m), 806(w), 776(s), 642(m), 530(w) and 439(w).

$\mathrm{X}$-ray structure determination: The intensity data were collected on a SuperNova X-ray diffractometer with graphite monochromated Mo- $K \alpha$ radiation $(\lambda=0.71073 \AA)$ by using a $\omega$ scan technique. CrystalClear software was used for data reduction and empirical absorption corrections. ${ }^{14}$ The structures were solved by the direct methods using the Siemens SHELXTL ${ }^{\mathrm{TM}}$ Version 5 package of crystallographic software. ${ }^{15}$ The difference Fourier maps based on the atomic positions yield non-hydrogen atoms and they were refined anisotropically. The hydrogen atom positions were generated theoretically and allowed to ride on their respective parent atoms, as well as included in the structure factor calculations with assigned isotropic thermal parameters, but were not refined. The structures were refined using a full-matrix leastsquares refinement on $F^{2}$. Crystallographic data are listed in Table 1, and selected bond distances and bond angles are given in Table 2. CCDC 1571940 (1) and 1571939 (2) contain the supplementary crystallographic data for this paper. These data can be made available free of charge via www.ccdc.cam.ac.uk/data_request/cif, by emailing data_request@ccdc.cam.ac.uk or by contacting CCDC.

Table 1

Summary of Crystallographic Data and Structure Analysis for $\mathbf{1}$ and $\mathbf{2}$

\begin{tabular}{lll}
\hline Complex & $\mathbf{1}$ & $\mathbf{2}$ \\
Formula & $\mathrm{C}_{12} \mathrm{H}_{16} \mathrm{Cl}_{4} \mathrm{CuN}_{2}$ & $\mathrm{C}_{12} \mathrm{H}_{16} \mathrm{Cl}_{4} \mathrm{CuN}_{2}$ \\
Formula weight & 393.61 & 393.61 \\
color & yellow & yellow \\
Crystal size $/ \mathrm{mm}^{3}$ & 0.170 .090 .05 & 0.280 .250 .21 \\
Crystal system & monoclinic & orthorhombic \\
Space group & $C 2 / c$ & $F d d 2$ \\
$a(\AA)$ & $16.4981(12)$ & $25.625(2)$ \\
$b(\AA)$ & $7.9064(4)$ & $31.7054(15)$ \\
$c(\AA)$ & $13.2230(7)$ & $7.7164(4)$ \\
$\beta\left({ }^{\circ}\right)$ & $116.967(6)$ & 90 \\
$V\left(\AA^{3}\right)$ & $1537.27(16)$ & $6269.1(7)$ \\
$Z$ & 4 & 16 \\
$2 \theta_{\text {max }}\left({ }^{\circ}\right)$ & 50 & 50 \\
Index ranges & $-18 \leq \mathrm{h} \leq 19,-8 \leq \mathrm{k} \leq 9,-15 \leq \mathrm{l} \leq 15$ & $-12 \leq \mathrm{h} \leq 30,-37 \leq \mathrm{k} \leq 36,-9 \leq \mathrm{l} \leq 8$ \\
Reflections collected & 4305 & 4831 \\
Independent, observed reflections & $1356,1249(0.0187)$ & $2362,2323(0.0125)$ \\
$\left(R_{\text {int }}\right)$ & & \\
\hline
\end{tabular}


Table 1 (continued)

\begin{tabular}{lll}
\hline$d_{\text {calcd. }}\left(\mathrm{g} / \mathrm{cm}^{3}\right)$ & 1.701 & 1.668 \\
$\mu\left(\mathrm{mm}^{-1}\right)$ & 2.102 & 2.062 \\
$T(\mathrm{~K})$ & $293(2)$ & $293(2)$ \\
$F(000)$ & 796 & 3184 \\
$R 1, w R 2$ & $0.0264,0.0659$ & $0.0305,0.0695$ \\
$S$ & 1.062 & 1.030 \\
Largest and Mean $\Delta / \sigma$ & 0,0 & 0,0 \\
$\Delta \rho(\max , \min )\left(\mathrm{e} / \AA^{3}\right)$ & $0.501,-0.413$ & $0.611,-0.514$ \\
\hline
\end{tabular}

Table 2

Selected bond distances / $/ \AA$ and bond angles $/{ }^{\circ}$ for $\mathbf{1}$ and $\mathbf{2}$

Complex 1

\begin{tabular}{|c|c|c|c|}
\hline $\mathrm{Cu}(1)-\mathrm{Cl}(1)$ & $2.2510(7)$ & $\mathrm{Cl}(1)-\mathrm{Cu}(1)-\mathrm{Cl}(2) \# 1$ & $95.42(2)$ \\
\hline $\mathrm{Cu}(1)-\mathrm{Cl}(2)$ & $2.2771(6)$ & $\mathrm{Cl}(1) \# 1-\mathrm{Cu}(1)-\mathrm{Cl}(2) \# 1$ & $98.69(2)$ \\
\hline $\mathrm{Cu}(1)-\mathrm{Cl}(1) \# 1$ & $2.2510(7)$ & $\mathrm{Cl}(1)-\mathrm{Cu}(1)-\mathrm{Cl}(2)$ & $98.69(2)$ \\
\hline $\mathrm{Cu}(1)-\mathrm{Cl}(2) \# 1$ & $2.2771(6)$ & $\mathrm{Cl}(1) \# 1-\mathrm{Cu}(1)-\mathrm{Cl}(2)$ & $95.42(2)$ \\
\hline $\mathrm{Cl}(1)-\mathrm{Cu}(1)-\mathrm{Cl}(1) \# 1$ & $137.06(5)$ & $\mathrm{Cl}(2) \# 1-\mathrm{Cu}(1)-\mathrm{Cl}(2)$ & $140.78(4)$ \\
\hline \multicolumn{4}{|c|}{ Symmetry codes: $\# 1-\mathrm{x}+1, \mathrm{y},-\mathrm{z}+1 / 2$. } \\
\hline \multicolumn{4}{|c|}{ Complex 2} \\
\hline $\mathrm{Cu}(1)-\mathrm{Cl}(1)$ & $2.2350(18)$ & $\mathrm{Cl}(2)-\mathrm{Cu}(1)-\mathrm{Cl}(3)$ & $116.80(8)$ \\
\hline $\mathrm{Cu}(1)-\mathrm{Cl}(2)$ & $2.2113(16)$ & $\mathrm{Cl}(1)-\mathrm{Cu}(1)-\mathrm{Cl}(3)$ & $102.27(6)$ \\
\hline $\mathrm{Cu}(1)-\mathrm{Cl}(3)$ & $2.2401(14)$ & $\mathrm{Cl}(2)-\mathrm{Cu}(1)-\mathrm{Cl}(4)$ & $98.72(7)$ \\
\hline $\mathrm{Cu}(1)-\mathrm{Cl}(4)$ & $2.2586(16)$ & $\mathrm{Cl}(1)-\mathrm{Cu}(1)-\mathrm{Cl}(4)$ & $115.17(7)$ \\
\hline $\mathrm{Cl}(2)-\mathrm{Cu}(1)-\mathrm{Cl}(1)$ & $116.38(9)$ & $\mathrm{Cl}(3)-\mathrm{Cu}(1)-\mathrm{Cl}(4)$ & $107.82(7)$ \\
\hline
\end{tabular}

\section{RESULTS AND DISCUSSION}

\section{General procedure}

With regard to both phases, the starting materials do not include the 2,2'-dimethyl-2,2'bipyridinium moiety, but it exists in the final products. Therefore, an in situ reaction happened, ${ }^{16}$ i.e. the 2,2'-dimethyl-2,2'-bipyridinium moiety is obtained from the in situ reaction of 2,2'-bipyridine, methanol and concentrated hydrochloric acid. As shown in Table 1, complex 1 crystallizes in the space group $C 2 / c$ of the monoclinic system with four formula units in a cell, while complex 2 crystallizes in the space group $F d d 2$ of the orthorhombic system with sixteen formula units in a cell. The density is $1.701 \mathrm{~g} / \mathrm{cm}^{3}$ and $1.668 \mathrm{~g} / \mathrm{cm}^{3}$ for $\mathbf{1}$ and $\mathbf{2}$, respectively.

\section{Crystal structure}

X-ray diffraction analysis reveals that the structure of complex 1 consists of 2,2'-dimethyl2,2'-bipyridinium cations and $\left[\mathrm{CuCl}_{4}\right]^{2-}$ anions, as shown in Fig. 1. All crystallographically independent atoms except for $\mathrm{Cul}$ are resided at general positions. The copper ion is tetrahedrally bounded by four chlorine atoms to form a $\left[\mathrm{CuCl}_{4}\right]^{2-}$ anion. The bond length of $\mathrm{Cu}-\mathrm{Cl}$ ranges from 2.2510(7) to 2.2771(6) $\AA$ with an average value of 2.264(7) $\AA$, which is normal and similar to the counterparts found in the literature. ${ }^{17-21}$ For the requirement of charge balance, 2,2'-dimethyl-2,2'-bipyridinium moieties must be protonated at the nitrogen atoms. The bond angle of $\mathrm{Cl}-\mathrm{Cu}-\mathrm{Cl}$ is in a range of $95.42(2)^{\circ}-140.78(4)^{\circ}$. Two pyridyl rings of each 2,2'-bipyridine molecule are twisted with respect to each other and the dihedral angle is $57.05^{\circ}$. The deviation of the atoms on the pyridyl rings is in a small span from $-0.008 \AA$ to $+0.007 \AA$ apart from their ring plane. The result of the bond valence calculation shows that the copper ion is in a +2 oxidation state $[\mathrm{Cu}(1): 1.961] .^{22}$ The 2,2'-dimethyl2,2'-bipyridinium cations and $\left[\mathrm{CuCl}_{4}\right]^{2-}$ anions are linked via hydrogen bonds to yield a 2-D supramolecular layer, as shown in Fig. 2. Several compounds with similar hydrogen bonds have been documented so far. ${ }^{23,24}$

X-ray diffraction analysis reveals that the structure of complex $\mathbf{2}$ also consists of 2,2'dimethyl-2,2'-bipyridinium cations and $\left[\mathrm{CuCl}_{4}\right]^{2-}$ anions, as shown in Fig. 3. All crystallographically 
independent atoms are resided at general positions. The copper ion is also tetrahedrally bounded by four chlorine atoms to form $\mathrm{a}\left[\mathrm{CuCl}_{4}\right]^{2-}$ anion. The bond length of $\mathrm{Cu}-\mathrm{Cl}$ ranges from 2.2113(16) to $2.2586(16) \AA$ with an average value of 2.236(16) $\AA$, which is $0.028 \AA$ shorter than that in $\mathbf{1}$. For the requirement of charge balance, 2,2'-dimethyl-2,2'bipyridinium moieties must be also protonated at the nitrogen atoms. The bond angle of $\mathrm{Cl}-\mathrm{Cu}-\mathrm{Cl}$ is in a range of $98.72(7)^{\circ}-116.80(8)^{\circ}$ and the maximum value $116.80(8)^{\circ}$ is obviously smaller than that $140.78(4)^{\circ}$ in $\mathbf{1}$. Two pyridyl rings of each 2,2'-bipyridine molecule are twisted with respect to each other and the dihedral angle is $72.53^{\circ}$, obviously larger than that $57.05^{\circ}$ in 1 . The deviation of the atoms on the pyridyl rings is in a span from $-0.025 \AA$ to $+0.016 \AA$ apart from their ring plane. The result of the bond valence calculation shows that the copper ion is in a +2 oxidation state $[\mathrm{Cu}(1): 2.115]$. The 2,2'-dimethyl2,2'-bipyridinium cations and $\left[\mathrm{CuCl}_{4}\right]^{2-}$ anions are linked via $\mathrm{C}-\mathrm{H} \cdots \mathrm{Cl}$ hydrogen bonds to yield a 2-D supramolecular layer, as shown in Fig. 4. The 2-D layers are further interconnected by $\mathrm{C}-\mathrm{H} \cdots \mathrm{Cl}$ hydrogen bonds to give a 3-D supramolecular framework, as shown in Fig. 5. Several compounds with similar hydrogen bonds have been reported previously. ${ }^{23,24}$
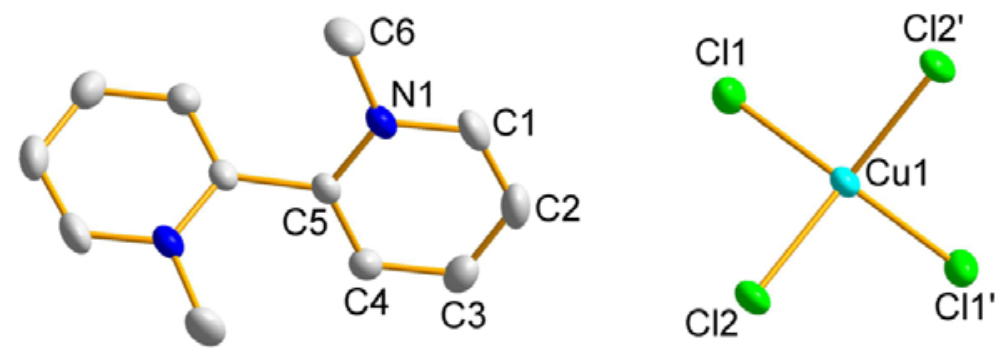

Fig. 1 - ORTEP-plot of 1 with 50\% thermal ellipsoids. Hydrogen atoms are omitted for clarity.

[Symmetry codes: (') $-x+1, y,-z+1 / 2]$.

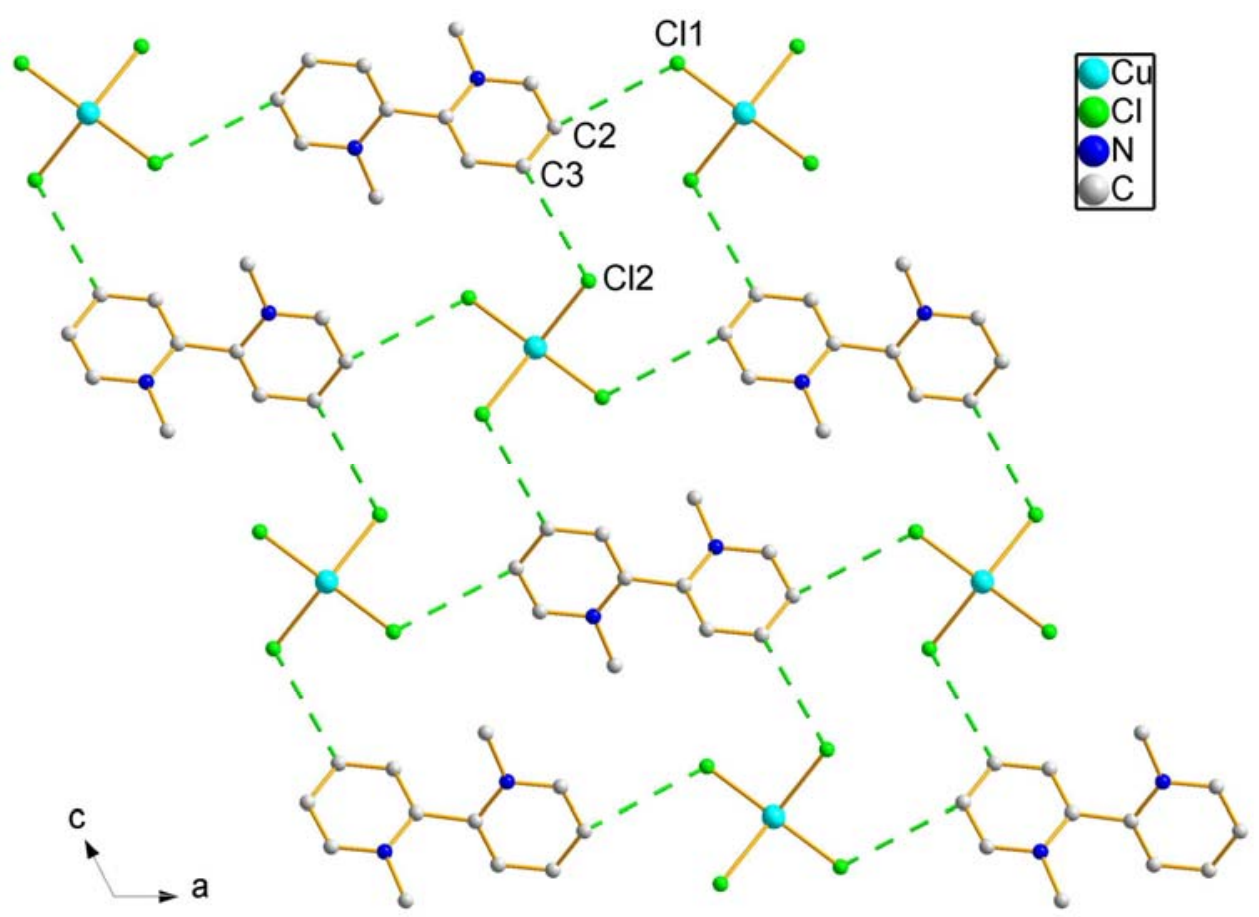

Fig. 2 - The 2-D layer of 1 formed by hydrogen bonds and the dashed lines represent hydrogen bonds $\left(\AA,^{o}\right): \mathrm{C}(2)-\mathrm{H}(2 \mathrm{~A}) \cdots \mathrm{Cl}(1)(1-x$, $1-y,-z) 3.506(3), 137 ; \mathrm{C}(3)-\mathrm{H}(3 \mathrm{~A}) \cdots \mathrm{Cl}(2)(1 / 2-x, 1 / 2+y,-1 / 2-z) 3.670(3), 177$. 


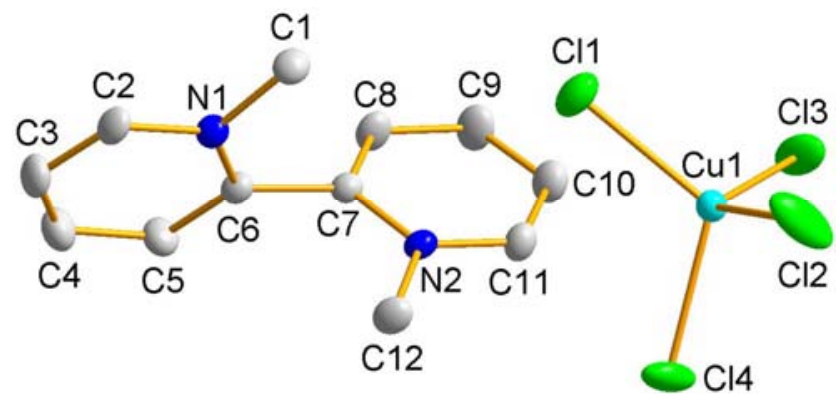

Fig. 3 - ORTEP-plot of 2 with 25\% thermal ellipsoids. Hydrogen atoms are omitted for clarity.

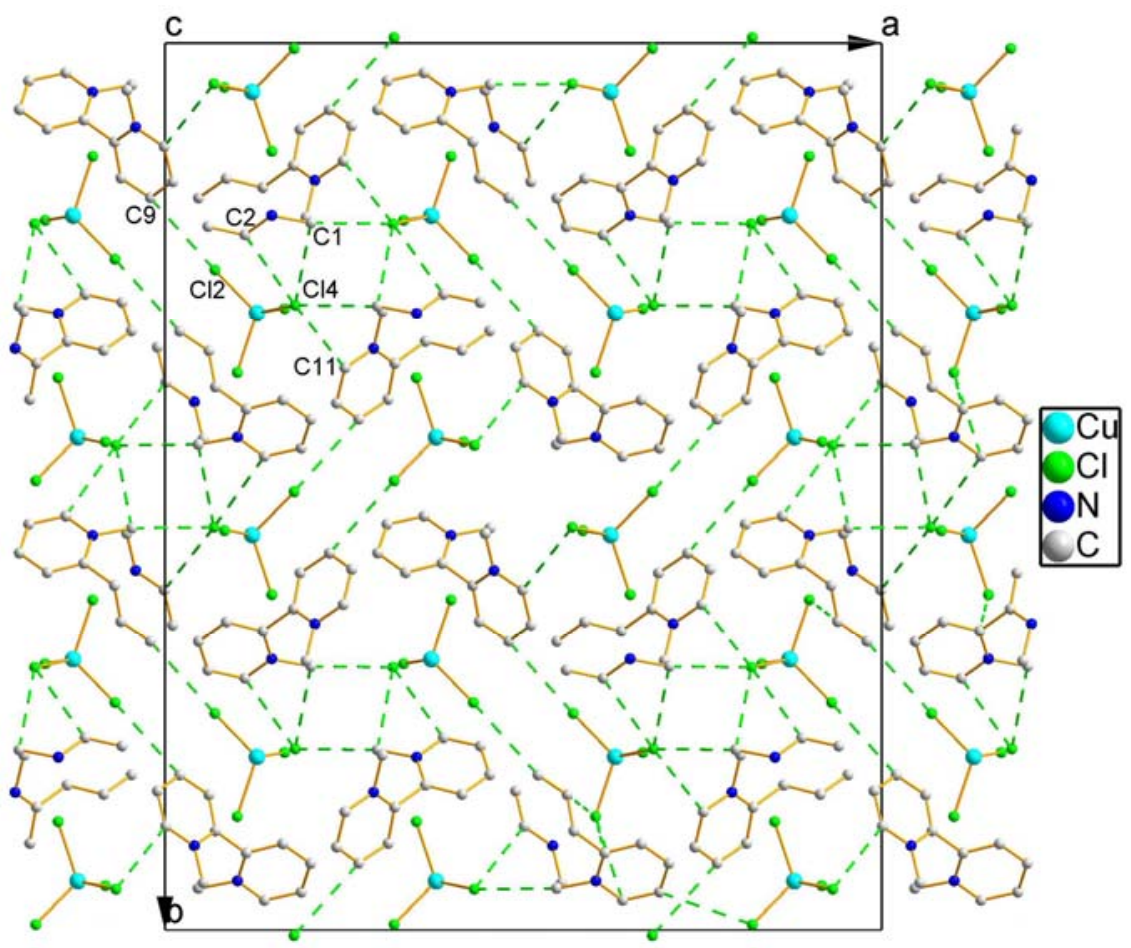

Fig. 4 - The 2-D layer of $\mathbf{2}$ formed by hydrogen bonds and the dashed lines represent hydrogen bonds.

\section{Fluorescence Spectra}

Taking into account the possible photoluminescent property of 2,2'-bipyridine, the photoluminescence of both phases was investigated at room temperature (Fig. 6 and Fig. 7). The solid-state excitation spectra of $\mathbf{1}$ show that the effective energy absorption mainly takes place in the ultraviolet region of the range 330-370 $\mathrm{nm}$. The excitation band of complex 1 under the green emission of $507 \mathrm{~nm}$ possesses one band at $351 \mathrm{~nm}$. We further measured the corresponding emission spectrum and it was shown as the solid line in Fig. 6. As for complex 1, the emission spectrum show one emission band at $507 \mathrm{~nm}$ under the excitation of $351 \mathrm{~nm}$. The solidstate excitation spectra of $\mathbf{2}$ shows that the effective energy absorption mainly takes place in the ultraviolet region of the range 265-295 $\mathrm{nm}$. The excitation band of complex 2 under the red emission of $716 \mathrm{~nm}$ possesses one band at $281 \mathrm{~nm}$. We further measured the corresponding emission spectrum of $\mathbf{2}$ and it was shown as the solid line in Fig. 7. As for complex 2 , the emission spectrum show one emission band at $716 \mathrm{~nm}$ under the excitation of $281 \mathrm{~nm}$. As a result, complexes $\mathbf{1}$ and $\mathbf{2}$ have obviously different photoluminescent emission bands in green or red region of the light spectrum.

Some other complexes with the bipyridinium cations have been documented and their photoluminescent emission bands can be assigned to the ligand-to ligand charge-transfer (LLCT, from the halide ions to the bipyridinium moiety) transition, as revealed by the theoretical calculations. ${ }^{25,26}$ Therefore, the photoluminescent emission bands of complexes $\mathbf{1}$ and 2 can probably be assigned to the ligand-to ligand charge-transfer (LLCT, from the halide ions to the bipyridinium moiety) transition. 


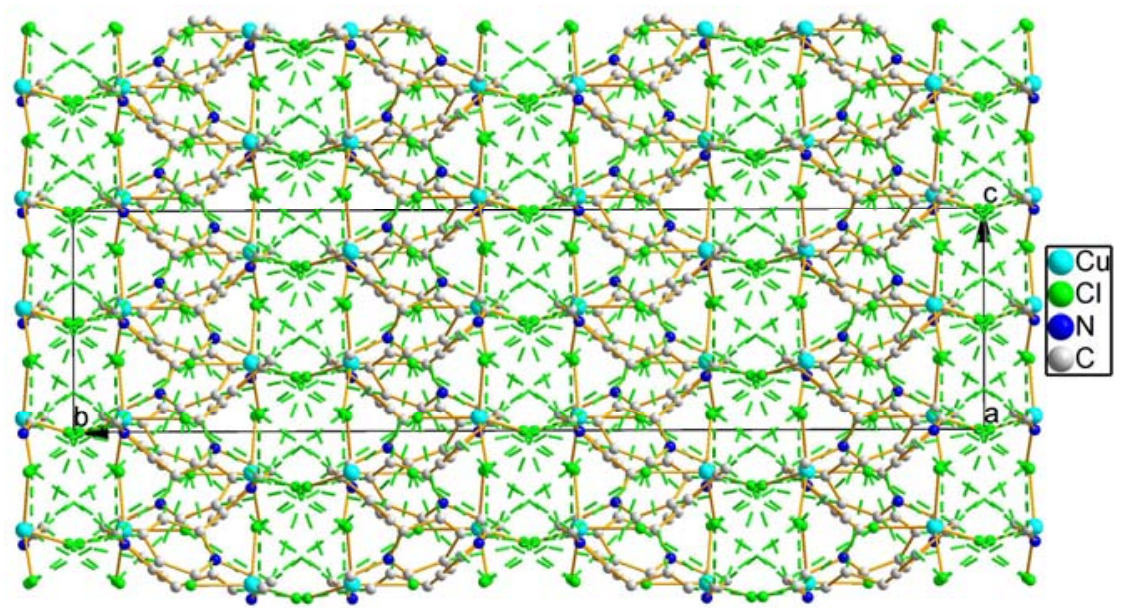

(a)

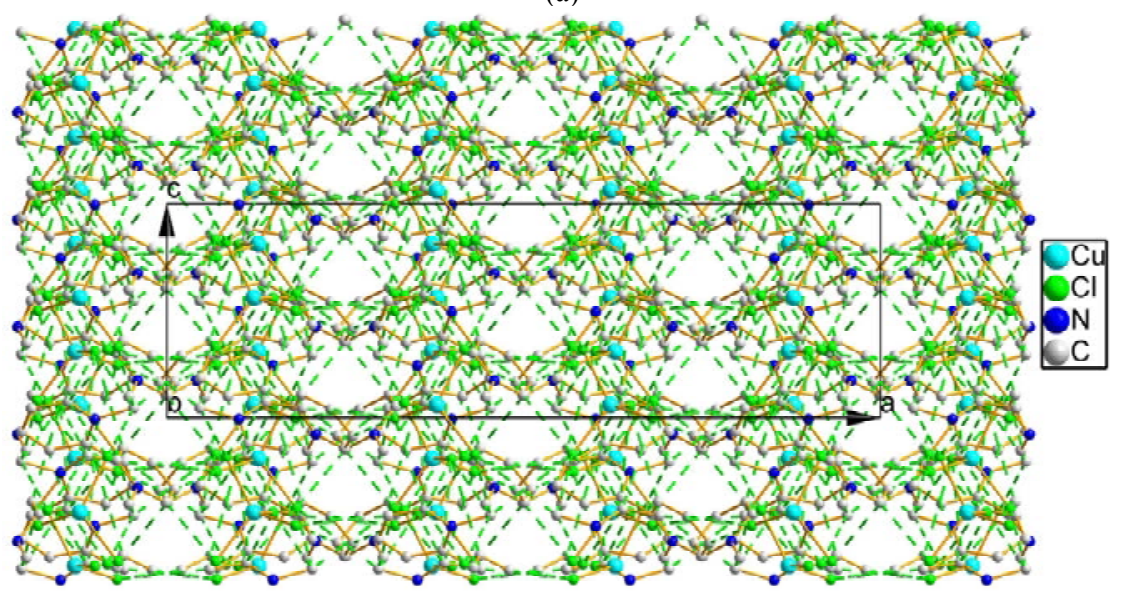

(b)

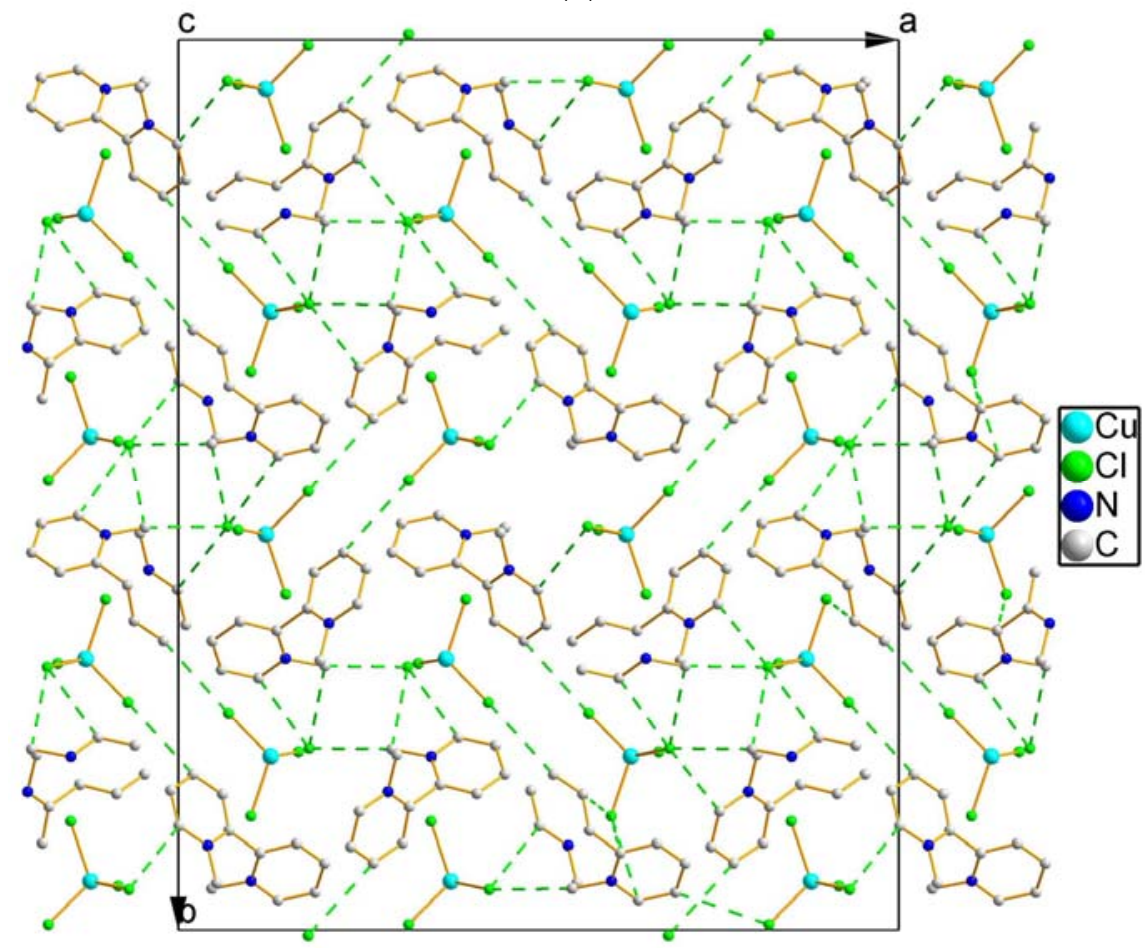

(c)

Fig. 5 - Packing diagram of 2 viewed from different directions with the dashed lines representing hydrogen bonds $\left(\AA,{ }^{\circ}\right)$ : $\mathrm{C}(1)$ $\mathrm{H}(1 \mathrm{~A}) \cdots \mathrm{Cl}(4)(-x,-y, 1+z) 3.721(6), 166 ; \mathrm{C}(2)-\mathrm{H}(2 \mathrm{~A}) \cdots \mathrm{Cl}(4)(-x,-y, 1+z) 3.678(6), 160 ; \mathrm{C}(9)-\mathrm{H}(9 \mathrm{~A}) \cdots \mathrm{Cl}(2)(1 / 4-x, 1 / 4+y, 1 / 4+z)$ 3.483(5), 130; $\mathrm{C}(11)-\mathrm{H}(11 \mathrm{~A}) \cdots \mathrm{Cl}(4) 3.568(5), 159$. 


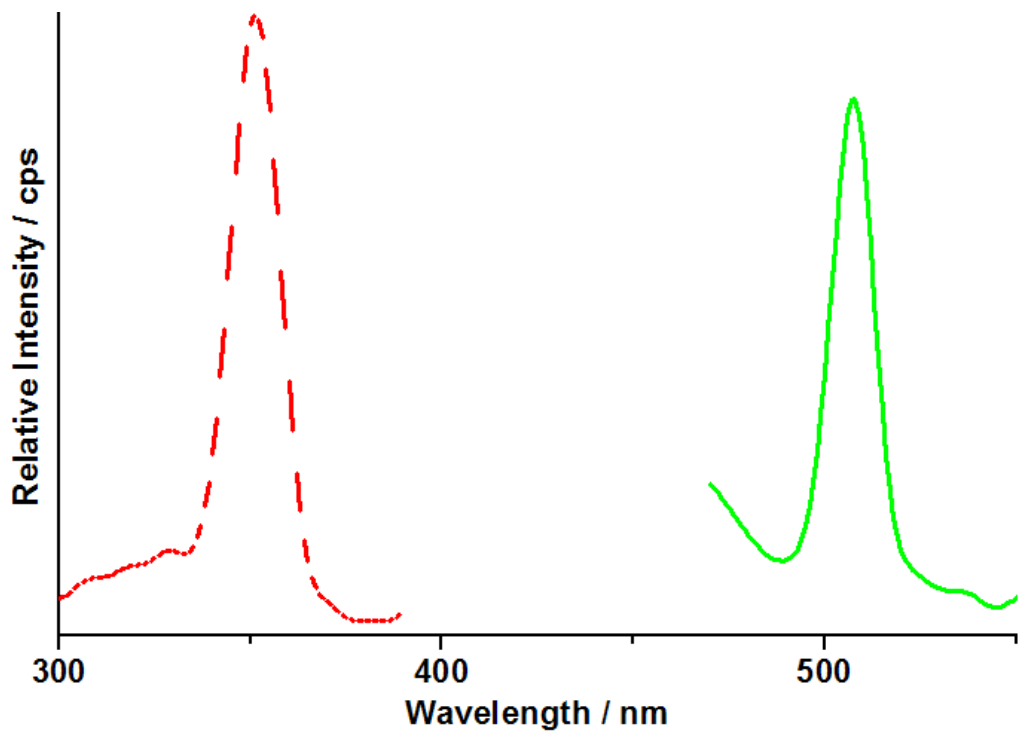

Fig. 6 - Solid-state photoluminescent spectra of $\mathbf{1}$ : solid plot for emission spectrum and dashed plot for excitation spectrum.

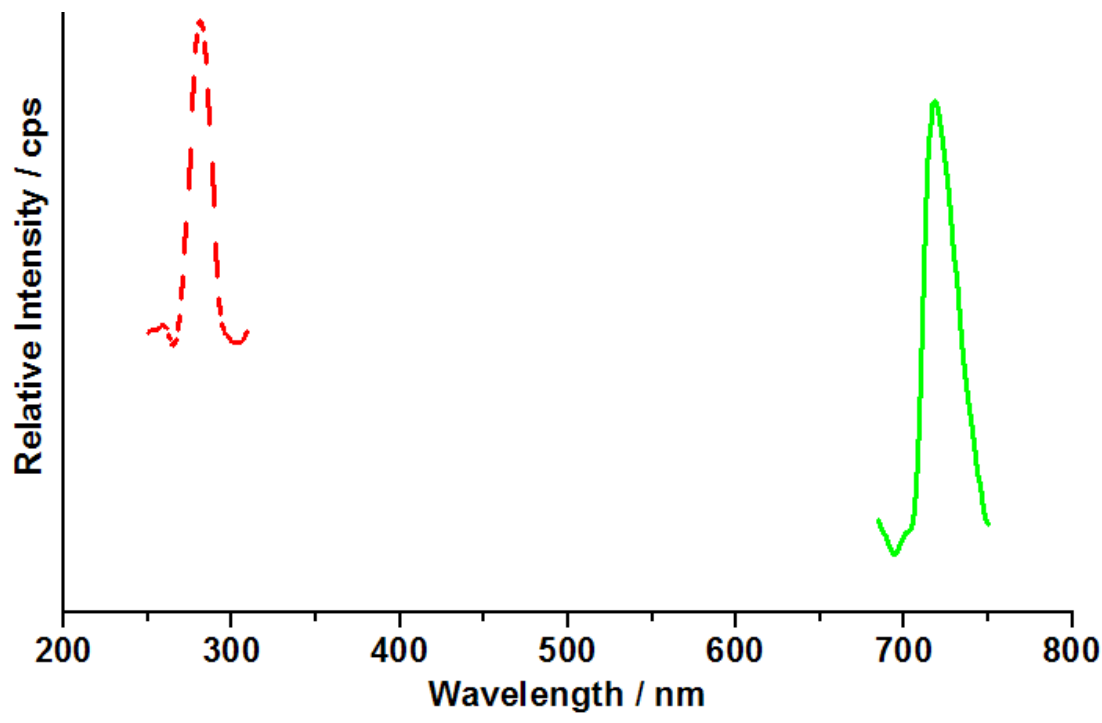

Fig. 7 - Solid-state photoluminescent spectra of $\mathbf{2}$ : solid plot for emission spectrum and dashed plot for excitation spectrum.

\section{Solid-state diffuse reflectance spectrum}

The solid-state diffuse reflectance spectra of both complexes were recorded at room temperature with powder samples. The values of the energy band gaps for both complexes were determined by extrapolating from the linear part of the absorption edges. Optical absorption spectra reveal the presence of an energy band gap of $1.53 \mathrm{eV}$ and $2.23 \mathrm{eV}$ for 1 and 2, respectively (Figs. 8-10), which suggests that both complexes may be a potential narrow-gap semiconductor. The slow slope of the optical absorption edge for $\mathbf{1}$ and $\mathbf{2}$ is indicative of the existence of indirect transitions. ${ }^{27}$ The optical absorption of $\mathbf{1}$ and $\mathbf{2}$ has likely originated from the charge-transfer excitations mainly from the p-like valence band of the chloride ligands to the 4s-like conduction band of the copper center. The energy band gaps of $1.53 \mathrm{eV}$ and $2.23 \mathrm{eV}$ for complexes $\mathbf{1}$ and $\mathbf{2}$ are close to those of GaAs $(1.4 \mathrm{eV}), \mathrm{CdTe}(1.5 \mathrm{eV})$ and $\mathrm{CuInS}_{2}$ $(1.55 \mathrm{eV})$, which are well-known for highly efficient photovoltaic compounds. ${ }^{28,29}$ 


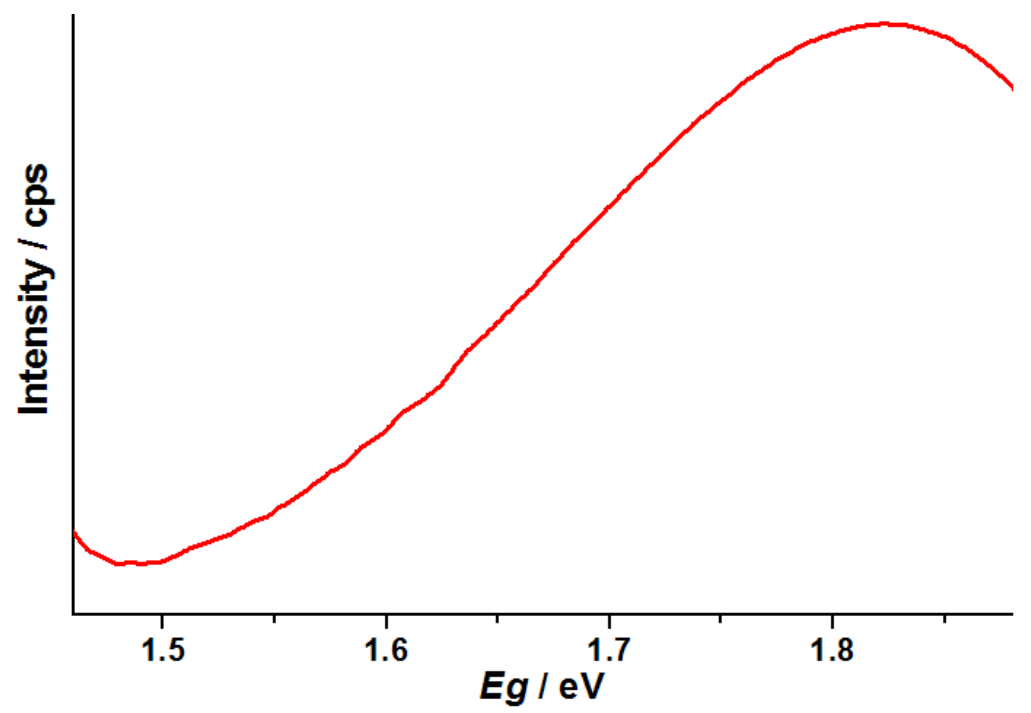

Fig. 8 - Solid-state diffuse reflectance spectrum of $\mathbf{1}$.

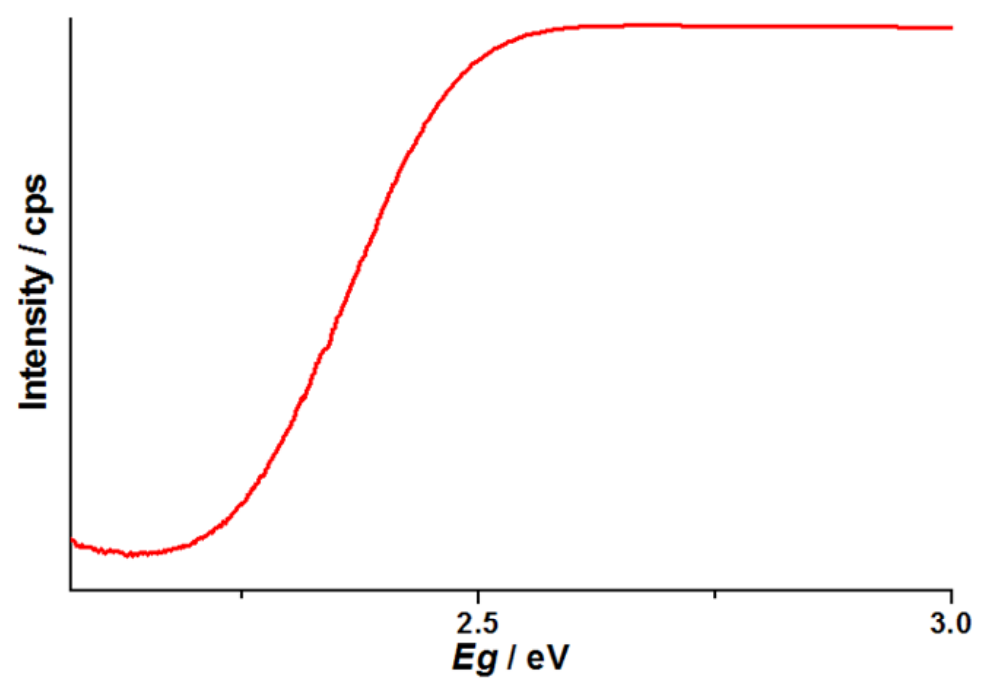

Fig. 9 - Solid-state diffuse reflectance spectrum of 2.

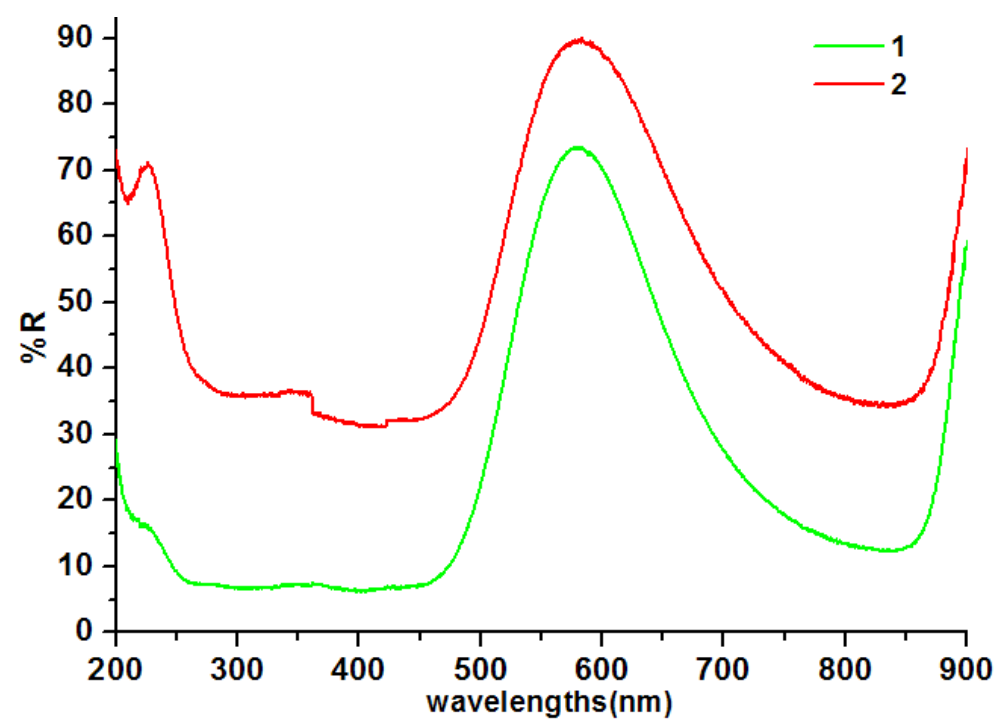

Fig. 10 - A stack of the solid state diffuse reflectance spectra in nm of $\mathbf{1}$ and $\mathbf{2}$. 


\section{CONCLUSIONS}

In brief, using an in situ reaction, we have prepared a copper complex with two phases. The $\alpha$ phase crystallizes in the space group $C 2 / c$ of the monoclinic system with four formula units in a cell, while the $\beta$ phase crystallizes in the space group $F d d 2$ of the orthorhombic system with sixteen formula units in a cell. The $\alpha$ phase is characteristic of an isolated structure and a 2-D supramolecular layer, while the $\beta$ phase features an isolated structure and a 3-D supramolecular framework. Photoluminescent investigation reveals that they display emissions in the green and red regions for $\alpha$ and $\beta$ phase, respectively. Optical absorption spectra reveal the presence of an energy band gap of $1.53 \mathrm{eV}$ and $2.23 \mathrm{eV}$ for $\alpha$ and $\beta$ phase, respectively. These different properties could be resulted from different structural geometries. Further systematically experimental and theoretical investigations on the relationship between the structures and properties are in progress in our lab.

Acknowledgemets. We gratefully acknowledge the financial support of the National Natural Science Foundation (51363009,21764007), and Jiangxi Provincial Department of Education's Item of Science and Technology (GJJ151217, GJJ160745), the Science and Technology Plan project Fund of Jiangxi Provincial Health Planning Commission (20194083), and Natural Science Foundation project of Jinggangshan Univesity (JZo9029).

\section{REFERENCES}

1. S. Samanta, S. Sanyal, M. Maity, M. Chaudhury and S. Ghosh, J. Lumin., 2017, 190, 403.

2. S. Saha and M. N. Roy, Chem. Phys. Lett., 2017, 684, 44.

3. J. Liu, C. S. Y. Tan, Y. Lan and O. A. Scherman, J. Polym. Sci. Pol. Chem., 2017, 55, 3105.

4. B. Ghanbari, M. Mandavian and A. M. Garcia-Deibe, J. Mol. Struct., 2017, 1144, 360.

5. J. Soleimannejad, F. Moghzi, S. Hooshmand, Z. Dankoob, M. Ardalani and M. Shamsipur, Polyhedron, 2017, 133, 24.

6. Y. Y. Yang, L. X. Zhou, Y. Q. Zheng, H. L. Zhu and W. Y. Li, J. Solid State Chem., 2017, 253, 211.
7. M. Bar, D. Maity, K. Das and S. Baitalik, Sensor Actuat B-Chem., 2017, 251, 208.

8. Z. Yao, W Chen and R. Hu. Z. Kristallogr., 2015, 230, 139.

9. S. E. Domínguez and F. Fagalde, Inorg. Chem. Commun., 2017, 77, 31 .

10. Y. Liu, L.-Z. Tang and S.-Z. Zhan, Inorg. Chem. Commun., 2017, 75, 49.

11. Z. Yao, W Chen and R. Hu. Indian J Chem, Sec A, 2015, 54, 489.

12. W. W. Wendlandt and H. G. Hecht, "Reflectance Spectroscopy", Interscience Publishers, New York, 1966.

13. G. Kortüm, "Reflectance Spectroscopy", Springer Verlag, New York, 1969.

14. Rigaku, CrystalClear Version 1.35, Rigaku Corporation, 2002.

15. Siemens, SHELXTL ${ }^{\mathrm{TM}}$ Version 5 Reference Manual, Siemens Energy \& Automation Inc., Madison, Wisconsin, USA, 1994.

16. Z. Yao and W. Chen, Crystallogr. Rep., 2017, 62, 1017.

17. G. Ryu and K. Son, J. Solid State Chem., 2016, 237, 358.

18. T. Dużak, B. Zarychta and V. V. Olijnyk, Inorg. Chim. Acta, 2011, 365, 235.

19. A. G. Majouga, E. K. Beloglazkina, A. V. Yudina, A. V. Mironov and N. V. Zyk, Inorg.Chem. Commun., 2015, 51,114 .

20. B. Gustafsson, M. Håkansson and S. Jagner, Inorg. Chim. Acta, 2003, 350, 209.

21. D. O. Zinyakhina, O. I. Siidra, D. O. Charkin, E. V. Nazarchuk and R. S. Bubnova, Inorg. Chem. Commun., 2016, 71,94 .

22. I. D. Brown and D. Altermat, Acta Crystallogr. B., 1985, 41, 244.

23. H. Luo, L. Zhu and Q. Wang, Crystallogr. Rep., 2015, 60, 1080.

24. Z. Yao, W. Chen and R. Hu, Indian J. Chem., 2015, 54A, 489.

25. W.-T. Chen, R.-H. Hu, Z.-G. Luo, H.-L. Chen, X. Zhang and J. Liu. Chinese J. Struct. Chem. 2014, 33, 1141.

26. W.-T. Chen, R.-H. Hu, Z.-G. Luo, H.-L. Chen, X. Zhang and J. Liu. Indian J Chem, Sec A, 2014, 53, 294.

27. F. Q. Huang, K. Mitchell and J. A. Ibers, Inorg. Chem., 2001, 40, 5123.

28. P. Dürichen and W. Bensch, Eur. J. Solid State Inorg. Chem., 1997, 34, 1187.

29. R. Tillinski, C. Rumpf, C. Näther, P. Duerichen, I. Jess, S. A. Schunk and W. Bensch, Z. Anorg. Allg. Chem., 1998, 624, 1285 . 

$\longrightarrow$ 